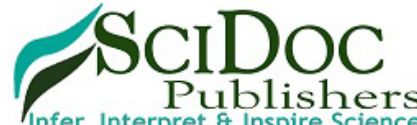

\author{
International Journal of Dentistry and Oral Science (IJDOS) \\ ISSN: 2377-8075
}

\title{
Prosthetic Status And Treatment Need Of The General Population Of Arcot (Vellore, Tamil Nadu) In Relation To Sociodemographic Characteristics: A Cross Sectional Study
}

Research Article

Syed Ali Peeran1*, Sunil Kumar²

${ }^{1}$ Doctorate Student, Department of Prosthodontics, Maharaj Vinayak Global University, Jaipur, Rajasthan, India.

${ }^{2}$ Professor \& Head, Department of Prosthodontics, Maharaj Vinayak Global University, Jaipur, Rajasthan, India.

\section{Abstract}

Introduction: Very few studies have been conducted in the Arcot (Vellore city Tamil Nadu) about the prosthetic status and prosthetic needs of the population. Hence, this study was conducted to determine the prosthetic status and prosthetic needs of general population of Arcot. Additionally, we aimed to correlate the demographic characteristics and socioeconomic status, with the prosthetic status and needs of the general population of Arcot.

Materials and Methods: This population based cross-sectional survey was conducted among the general population of Arcot. The population to be studied was selected from the geographical boundaries of Arcot (4 urban and 4 rural). A simple random sampling was carried out. The data was collected from various public places such as schools, households, hospitals, hostels, colleges and various other places of work. All age groups were included in the study so that the results represent the status of the whole sample rather than particular age groups. The questionnaire was prepared which enquired about the age, gender, area of residence, education, occupation, family income, prosthetic status and needs. A single calibrated examiner with the help of an assistant examined the samples.

Results: A total number of 7000 subjects were included in the study in which $4702(67.17 \%)$ were males and $32.83 \%$ were females. Only subjects with permanent dentition were considered. Most samples ranged from 18 years and above up to 75 . As per convenience the sample was re-grouped into 14-17 years, $18-34$ years, 35-44 years, $45-64$ years and 65 years and above age groups. Most of the population had no prosthesis. Prosthetic needs in the present study were $41.7 \%$ in maxillary arch and mandibular arch. Correlation between prosthetic status and need with other characteristics was done by Spearman's rank correlation method. Positive correlation was observed between age, level of education and prosthetic status and needs. The occupation and prosthetic status were negatively correlated. Income was negatively correlated with prosthetic status and needs Conclusion: Most of the prosthetic needs of the studied population were unmet with prosthetic needs being approximately two-fold greater than the prosthetic status.

Keywords: Prosthetic Status; Prosthetic Needs.

\section{Introduction}

Oral health is an integral part of general health and plays an important role in improving the quality of life. The oral cavity is the port of entry for many diseases and presents several unique features that make it especially prone to occupational diseases. [1, 2] Every age group is susceptible to certain oral diseases. Also, as the age advances, changes can be observed in the tooth structure partly due to normal wear and tear and also, due to certain diseases that become. [3]
Loss of teeth could be a disturbing emotional experience for many people. [4] Tooth loss adversely affect the dietary intake and nutritional status of individuals. [5] Some people associate the loss of teeth with growing old, which may be emotionally disturbing. Tooth loss constitutes a final common pathway for most dental diseases and conditions including dental caries and periodontal diseases. This tooth loss can lead to substantial impacts on quality of life.[6] In order to prevent or improve the oral health-related quality of life, dentists frequently recommend replacement of teeth with either a fixed or removable prosthesis. [7]Dental prosthesis has the ability to reduce the deficits attributed to lost teeth,

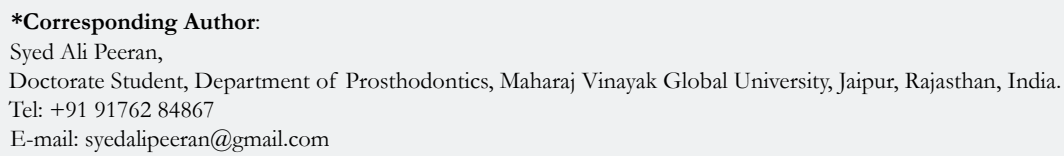

Citation: Syed Ali Peeran, Sunil Kumar. Prosthetic Status And Treatment Need Of The General Population Of Arcot (Vellore, Tamil Nadu) In Relation To Sociodemographic Characteristics: A Cross Sectional Study. Int J Dentistry Oral Sci. 2021;8(7):3538-3542. doi: http://dx.doi.org/10.19070/2377-8075-21000723

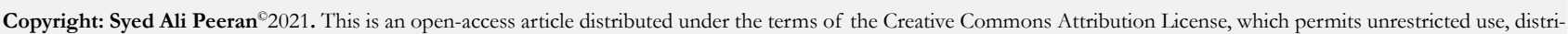
bution and reproduction in any medium, provided the original author and source are credited. 
because it improves their chewing ability, digestion, aesthetics, and as a result, their quality of life. [8, 9]

Various studies in the past have revealed that socioeconomic status; especially education level and income have a strong association with oral health. $[10,11]$ Findings from recent studies show that people with low and very low incomes are 5 times more likely to have a poor oral health status compared to those with high incomes. [12] In addition, a higher level of education is commonly related to better oral health and quality of life. [12] Education also ensures the possibility to attain and understand information regarding oral health. $[10,12]$

Very few studies have been conducted in the Arcot (Vellore city Tamil Nadu) about the prosthetic status and prosthetic needs of the population. The available data is scanty. This was the first known attempt to the author's knowledge to access and form a baseline data to describe the prosthetic status and treatment needs and socioeconomic data of the general population of Arcot. Hence, this study was conducted to determine the prosthetic status and prosthetic needs of general population of Arcot. Additionally, we aimed to correlate the demographic characteristics and socioeconomic status, with the prosthetic status and needs of the general population of Arcot.

\section{Materials And Methods}

Basic profile of Study area: Arcot is located at $12.9^{\circ} \mathrm{N} 79.33^{\circ} \mathrm{E}$. It has an average elevation of 164 meters (538 ft.) Arcot Town has a $7.49 \mathrm{~km} 2$ area with a population of 70000 as per the 2011 census. The Municipal office is situated nearly $1 / 4 \mathrm{~km}$ east from the bus stand. The town is located on the southern bank of Palar River, easily accessible from the capital of Tamil Nadu. Chennai is within $120 \mathrm{~km}$ and the district headquarters are within $25 \mathrm{~km}$. Arcot has been developing as a commercial centre for long time as it is connected to Chennai and Vellore by the National Highways-46 Ranipet to Krishnagiri Road (Arani to Chennai) passing through this town. Besides this, tourists see nick beauty namely Delhi Gate. This generates floating population to this town.13

Sampling Design: The population to be studied was selected from the geographical boundaries of Arcot. A simple random sampling was carried out.

Urban area: The following urban areas i.e., Arcot Municipality, Timiri Town panchayat, Vilapakkam town panchayat, Tajpura Census Town in the Arcot city were selected randomly.

Rural area: The following rural areas i.e., Agaram, Aroor, Durgam, Irungur, around Arcot city were selected randomly.

\section{Obtaining approval from the authorities}

Before the start of the study official permission was obtained from the concerned authorities. Ethical clearance to conduct the study was issued by the ethical clearance board, scientific committee, Faculty of Dentistry, Maharaj Vinayak Global University, Jaipur, Rajasthan.

\section{Study population, sampling and data collection}

The target population is general population of Arcot (Vellore city Tamil Nadu). Verbal consent to participate in the study will be taken from the participants, being assured that they will remain anonymous concerning their personal data. The data was collected from various public places such as schools, households, hospitals, hostels, colleges and various other places of work. All age groups were included in the study so that the results represent the status of the whole sample rather than particular age groups.

\section{Questionnaire}

A single page questionnaire was designed to be used to assess the oral hygiene practices habits and systemic diseases. The questionnaire was prepared in English; it was translated into vernacular language and retranslated into English to evade language errors. (Refer to Appendix-1)

The questionnaire enquires about the age, gender, area of residence, education, occupation, family income, prosthetic status and needs.

\section{Examiner and examination}

A single calibrated examiner with the help of an assistant examined the sample. W.H.O Type 3 examination was carried out. Examination was carried out in the nearest public dental centre with natural light to reduce diagnostic bias.

\section{Statistical analysis}

Descriptive and inferential statistical analyses were carried out in the present study. Results on continuous measurements were presented on Mean $\pm \mathrm{SD}$ and results on categorical measurement were presented in number $(\%)$. Level of significance was fixed at $\mathrm{p}=0.05$ and any value less than or equal to 0.05 was considered to be statistically significant. The data was presented as number and $\%$ for the categorical variables. The Spearman's rank correlation method was used to correlate the prosthetic status and needs with sociodemographic variables. The Statistical software IBM SPSS statistics 20.0 (IBM Corporation, Armonk, NY, USA) was used for the analyses of the data and Microsoft word and Excel were used to generate graphs, tables etc.

\section{Results}

In the present study most participants, 45.37 percent were aged 18-to-34-year category, followed by 27.74 percent aging from 45 - 64 years and only 10.57 percent were above 65 years. 67.17 percent were males and 32.8 were females. 55.17 percent belong to urban area and 44.8 percent belong to rural area. (Table 1)

In the present study only 6.6 percent were either professional or holding doctorates, 13 percent were graduates or postgraduates, 14.8 percent were intermediate level, 33 percent were high school passed outs, 12 percent were middle and primary school passed out. 20.6 percent of the sample was illiterate. In the present study 7.8 percent of the sample were professionals, 6.2 percent were semi-professionals, 4.3 percent were either shop owners, clerks or farmers, 8.6 percent were skilled workers, 9.5 percent were semiskilled workers, 9 percent were unskilled workers and 54.60 were unemployed (31.2 percent were unemployed. 23.4 percent of the 
sample was still studying). The income distribution is mentioned in table 3.

For the maxillary arch, 83.7 percent of the samples had no prosthesis, 8.7 percent had bridge, 3.3 percent were had more than one bridge, 1.7 percent had partial dentures, 0.8 percent was had both bridge and partial dentures. For mandibular arch, 86 percent of the samples had no prosthesis, 6.9 percent had bridge, 3.2 percent had more than one bridge, 1.8 percent were had partial dentures, 0.63 percent had both bridge and partial dentures whereas 1.5 percent of the sample were had fully removable dentures. (Table 3)

In the present study 58.3 percent of the sample did not require any prosthesis, 19.7 percent required single unit prosthesis, 13.1 percent required multiple unit prosthesis and 4.23 percent re- quired the combination of single and multiple unit prosthesis whereas 4.4 percent required full prosthesis. In the present study 58.3 percent of the sample did not require any prosthesis, 19.4 percent required single unit prosthesis, 12.7 percent required multiple unit prosthesis and 4.54 percent required the combination of single and multiple unit prosthesis where as 4.83 percent required full prosthesis. (Table 4)

Correlation between prosthetic status and need with other characteristics was done by Spearman's rank correlation method. Positive correlation was observed between age, level of education and prosthetic status and needs. The occupation and prosthetic status were negatively correlated. Income was negatively correlated with prosthetic status and needs.(Table 5)

Table 1. Distribution of respondents according to age groups.

\begin{tabular}{|c|c|c|c|}
\hline Variables & Sub-groups & $\mathbf{n}$ & $\mathbf{\%}$ \\
\hline \multirow{3}{*}{ Gender } & Male & 4702 & 67.17 \\
\cline { 2 - 4 } & Female & 2298 & 32.83 \\
\hline \multirow{4}{*}{ Age group } & $14-17$ & 18 & 0.26 \\
\cline { 2 - 4 } & $18-34$ & 3176 & 45.37 \\
\cline { 2 - 4 } & $35-44$ & 1124 & 16.06 \\
\cline { 2 - 4 } & $45-64$ & 1942 & 27.74 \\
\cline { 2 - 4 } & 65 \& Above & 740 & 10.57 \\
\hline \multirow{2}{*}{ Area of residence } & Rural & 3138 & 44.83 \\
\cline { 2 - 4 } & Urban & 3862 & 55.17 \\
\hline
\end{tabular}

Table 2. Distribution of respondents according to Level of Education and occupation.

\begin{tabular}{|c|c|c|}
\hline Education level & No & Percentage \\
\hline 1-Doctorate/profession & 462 & 6.6 \\
\hline $\begin{array}{c}\text { 2-Graduate/post grad- } \\
\text { uate }\end{array}$ & 912 & 13.03 \\
\hline 3-Intermediate & 1036 & 14.8 \\
\hline 4-High school & 2312 & 33.03 \\
\hline 5-Middle school & 410 & 5.86 \\
\hline 6-Primary school & 424 & 6.06 \\
\hline 7-Illiterate & 1444 & 20.63 \\
\hline \multicolumn{3}{|l|}{ Occupation } \\
\hline 1-Professional & 546 & 7.8 \\
\hline 2-Semi profession & 432 & 6.17 \\
\hline 3-Clerical/farmer/shop & 304 & 4.34 \\
\hline 4-Skilled worker & 600 & 8.57 \\
\hline 5-Semi-skilled worker & 664 & 9.49 \\
\hline 6-Un-skilled & 632 & 9.03 \\
\hline 7-Unemployed & 3822 & 54.6 \\
\hline \multicolumn{3}{|l|}{ Income } \\
\hline $800-3000$ & 698 & 10 \\
\hline $300-6000$ & 2104 & 30.1 \\
\hline $6001-10000$ & 3106 & 44.4 \\
\hline $10001-15000$ & 806 & 11.5 \\
\hline $15001-25000$ & 260 & 3.7 \\
\hline $25001-50000$ & 18 & 0.3 \\
\hline $50001-89000$ & 8 & 0.1 \\
\hline
\end{tabular}


Table 3. Distribution of respondents according to Maxillary Prosthetic status.

\begin{tabular}{|c|c|c|c|c|}
\hline \multirow{2}{*}{ Prosthetic status } & \multicolumn{2}{|c|}{ Maxillary } & \multicolumn{2}{c|}{ Mandibular } \\
\cline { 2 - 5 } & Number & $\mathbf{\%}$ & Number & $\mathbf{\%}$ \\
\hline No prosthesis & 5862 & 83.74 & 6018 & 85.97 \\
\hline Bridge & 606 & 8.66 & 482 & 6.89 \\
\hline More than one bridge & 230 & 3.29 & 222 & 3.17 \\
\hline Partial denture & 120 & 1.71 & 126 & 1.8 \\
\hline Both bridge and partial denture & 58 & 0.83 & 44 & 0.63 \\
\hline Full removable denture & 120 & 1.71 & 104 & 1.49 \\
\hline Not recorded & 4 & 0.06 & 4 & 0.06 \\
\hline
\end{tabular}

Table 4. Distribution of respondents according to maxillary and mandibular prosthetic needs.

\begin{tabular}{|c|c|c|c|c|}
\hline \multirow{2}{*}{ Prosthetic needs } & \multicolumn{2}{|c|}{ Maxillary } & \multicolumn{2}{c|}{ Mandibular } \\
\cline { 2 - 5 } & Number & Percentage & Number & Percentage \\
\hline No prosthesis needed & 4080 & 58.29 & 4082 & 58.31 \\
\hline Need of one unit prosthesis & 1380 & 19.71 & 1358 & 19.4 \\
\hline Need for multiunit prosthesis & 918 & 13.11 & 888 & 12.69 \\
\hline Combination of above & 296 & 4.23 & 318 & 4.54 \\
\hline Need for full prosthesis & 308 & 4.4 & 338 & 4.83 \\
\hline Not recorded & 18 & 0.26 & 16 & 0.23 \\
\hline
\end{tabular}

Table 5. Correlation between prosthetic status and needs with other sociodemographic characteristics by Spearman's rank correlation method.

\begin{tabular}{|c|c|c|c|c|}
\hline \multirow{2}{*}{ Factors } & \multicolumn{2}{|c|}{ prosthetic status } & \multicolumn{2}{|c|}{ Prosthetic needs } \\
\hline & maxillary & mandibular & Maxillary & Mandibular \\
\hline \multirow{2}{*}{ Age } & 0.187 & 0.200 & 0.407 & 0.396 \\
\hline & $\mathrm{P}=<0.001^{* *}$ & $\mathrm{P}=<0.001 * *$ & $\mathrm{P}=<0.001^{* *}$ & $\mathrm{P}=<0.001^{* *}$ \\
\hline \multirow{2}{*}{ Sex } & 0.038 & 0.019 & -0.029 & \multirow{2}{*}{$\begin{array}{c}-0.0389 \\
\mathrm{P}=0.0012^{*}\end{array}$} \\
\hline & $\mathrm{P}=0.0016^{*}$ & $\mathrm{P}=0.1214$ & $\mathrm{P}=0.0145^{*}$ & \\
\hline \multirow{2}{*}{ Place of residence } & 0.053 & 0.065 & -0.078 & -0.071 \\
\hline & $\mathrm{P}=<0.001 * *$ & $\mathrm{P}=<0.001 * *$ & $\mathrm{P}=<0.001 * *$ & $\mathrm{P}=<0.001 * *$ \\
\hline \multirow{2}{*}{ Levels of education } & 0.076 & 0.058 & 0.296 & 0.314 \\
\hline & $\mathrm{P}=<0.001^{* *}$ & $\mathrm{P}=<0.001^{* *}$ & $\mathrm{P}=<0.001 * *$ & $\mathrm{P}=<0.001^{* *}$ \\
\hline \multirow{2}{*}{ Occupations } & -0.072 & -0.078 & -0.017 & 0.003 \\
\hline & $\mathrm{P}=<0.001 * *$ & $\mathrm{P}=<0.001 * *$ & $\mathrm{P}=0.1607$ & $\mathrm{P}=0.7782$ \\
\hline \multirow{2}{*}{ Income } & -0.012 & -0.008 & -0.201 & -0.2 \\
\hline & $\mathrm{P}=0.2997$ & $\mathrm{P}=0.5255$ & $\mathrm{P}=<0.001 * *$ & $\mathrm{P}=<0.001 * *$ \\
\hline
\end{tabular}

$(\mathrm{p}<0.05$ - Significant*, $\mathrm{p}<0.001$ - Highly significant**)

\section{Discussion}

Presence of teeth is a very important aspect of happy and healthy life as it helps the individual to maintain proper general health. People having their missing teeth whether few or all realize the importance of teeth. Very few studies have been conducted about the prosthetic status and needs of general population as most of the studies are conducted either on elderly age groups or old age home inmates or special populations, but this study aims at knowing the prosthetic status and needs of the general population as teeth are important in all ages of life. This study was conducted in Arcot region, Vellore district in Tamil Nadu.

A total number of 7000 subjects were included in the study in which 4702 (67.17\%) were males and 32.83\% were females. Only subjects with permanent dentition were considered. Most samples ranged from 18 years and above up to 75 . As per convenience the sample was re-grouped into 14-17 years, 18-34 years, 35-44 years, 45-64 years and 65 years and above age groups. Most of the population had no prosthesis. Prosthetic needs in the present study were $41.7 \%$ in maxillary arch and mandibular arch. The bridge was the most common prosthesis used followed by complete and partial denture. Nagaraj, E., et al.[14] and Shah et al [3] had similar study findings. The low proportion of prosthesis may be due to the lack of awareness, financial concerns and misconceptions regarding prosthesis.

In the present study positive correlation was seen between the age and prosthetic status and need, i.e., as the age increased the prosthetic needs also increased significantly $(p<0.001)$ in both the arches. The reason of more prosthetic needs in elder age groups may be tooth loss would have been due to periodontal diseases which are common in elder age groups.[15] Females had lesser prosthetic needs than males. Males require more prosthesis than 
females. The findings are similar to study done by Shah et al [3] and Shenoy et al [16]. The reason may be habits such as use of tobacco, smoking and negligence of general dental health by men. [14] Similarly prosthetic status positively correlated with urban population as well as prosthetic need decreased in urban samples. The reason could be that large proportion of dentists resides in the urban population. Dentists to population ratio, there are 10 times more in cities than in villages in India.[17] Moreover, in rural areas the standard of living and economic status is low and dental treatment is therefore obviously neglected till tooth loss is the final result. $[17,18]$

In the present study, the prosthetic status was more in higher level occupation (professionals). The increased educational status was associated with better prosthetic status and lesser prosthetic need. The reason could be that the educated class would be more aware and recognize the importance of good dental health and go for preventive care. But with the less educated groups, extraction would be much common and knowledge on preventive care would be limited. The social pressure of maintaining the esthetics and function may be the driving force that influences the subjects in the upper class to get their missing teeth replaced.[19] Moreover those of a higher education status are more likely to be able to afford regular dental care than those of a lower education status. [14] In addition to this, the attitude and awareness toward dental care, and the cost of dental treatment might also be the significant factor.[11]

In the present study, there was no association between prosthetic status and income in our study, whereas, increased income was associated with decreased prosthetic need in both upper and lower arches. That is the people who had money could afford for dental treatments and save their teeth and poor people usually prefer extractions. 17

The results are similar to that of Shah et al3,Shah et al20, Bhardwaj et al11 and Hameed A et al10 where upper socioeconomic class had fewer prosthetic needs (both upper and lower) than middle, upper lower and lower socio economic class people. The socioeconomic status and education level had a strong association with oral health.

To know the prevalence of a disease and the treatment needs are the first step in the right direction to deal with the dental disease. However, our study had certain limitations. Firstly, the study population was conveniently selected hence reducing the external validity of the study. Nevertheless, the study area was selected by random selection and may accurately represent the population of Arcot. A nationwide evaluation of health services should carry out further epidemiological surveys on a larger scale with doorto-door data acquisition related to wealth, religion and caste on individual basis. This helps us to estimate the prosthetic status and need and associated factors.

\section{Conclusion}

This is the first study done to determine the prosthetic status and treatment needs of the general population of Arcot. The findings in this study revealed a significant relationship between sociodemographic variables and edentulism with age, educational level and socioeconomic status playing vital roles in edentulism and denture demand. Unmet prosthetic treatment needs existed in Arcot, indicating the existence of barriers to accessible dental care. A sizeable amount of population is also in need of dental prosthesis and the same needs immediate attention. The present results may serve as a baseline for the future evaluation of attitudes towards replacement of teeth.

\section{References}

[1]. Patil VV, Shigli K, Hebbal M, Agrawal N. Tooth loss, prosthetic status and treatment needs among industrial workers in Belgaum, Karnataka, India. J Oral Sci. 2012;54(4):285-92. Pubmed PMID: 23221153.

[2]. Schour I, Sarnat BG. Oral manifestations of occupational origin. J Am Med Asso 1964; 120: 1197-1207.

[3]. Shah N, Parkash H, Sunderam KR. Edentulousness, denture wear and denture needs of Indian elderly--a community-based study. J Oral Rehabil. 2004 May;31(5):467-76. Pubmed PMID: 15140173.

[4]. KATZ S, FORD AB, MOSKOWITZ RW, JACKSON BA, JAFFE MW. STUDIES OF ILLNESS IN THE AGED. THE INDEX OF ADL: A STANDARDIZED MEASURE OF BIOLOGICAL AND PSYCHOSOCIAL FUNCTION. JAMA. 1963 Sep 21;185:914-9. Pubmed PMID: 14044222.

[5]. Pallegedara C, Ekanayake L. Tooth loss, the wearing of dentures and associated factors in Sri Lankan older individuals. Gerodontology. 2005 Dec;22(4):193-9. Pubmed PMID: 16329226.

[6]. Locker D, Miller Y. Evaluation of subjective oral health status indicators. J Public Health Dent. 1994 Summer;54(3):167-76. Pubmed PMID: 7932353.

[7]. Eachempati P, Shenoy VK, Jain N, Singh S. Prosthodontic status and needs of elderly institutionalized residents in Mangalore: a prospective study. Indian J Dent Res. 2013 May-Jun;24(3):284-8. Pubmed PMID: 24025871.

[8]. Gonsalves WC, Wrightson AS, Henry RG. Common oral conditions in older persons. Am Fam Physician. 2008 Oct 1;78(7):845-52. Pubmed PMID: 18841733.

[9]. Bedi R, Gulati N, McGrath C. A study of satisfaction with dental services among adults in the United Kingdom. British dental journal. 2005 Apr; 198(7):433-7.

[10]. Hameed A, Ihsan S, Raza M, Irshad M, Khan A. Prosthetic status and needs in patients visiting dental teaching hospitals of Peshawar. The Professional Medical Journal. 2019 Oct 7;26(11):1835-43.

[11]. Bhardwaj VK, Veeresha KL, Sharma KR. Dental prosthetic status, prosthetic needs in relation to socioeconomic status of the state government employees in Shimla city (Himachal Pradesh) - A cross sectional study. J Int Soc Prev Community Dent. 2011 Jul;1(2):52-6. Pubmed PMID: 24478954.

[12]. Esan TA, Olusile AO, Ojo MA, Udoye CI, Oziegbe EO, Olasoji HO. Tooth loss among Nigerians treated in teaching hospitals: a national pilot study. J Contemp Dent Pract. 2010 Oct 14;11(5):017-24. Pubmed PMID: 20978720.

[13]. Arcot, Tamil Nadu- Wikipedia.

[14]. Nagaraj E, Mankani N, Madalli P, Astekar D. Socioeconomic factors and complete edentulism in north karnataka population. J Indian Prosthodont Soc. 2014 Mar;14(1):24-8. Pubmed PMID: 24604994.

[15]. Kumar DR, Raju DS, Naidu L, Deshpande S, Chadha M, Agarwal A. Prosthetic status and prosthetic needs amongst geriatric fishermen population of Kutch coast, Gujarat, India. Rocz Panstw Zakl Hig. 2015;66(2):167-71. Pubmed PMID: 26024406.

[16]. Shenoy RP, Hegde V. Dental prosthetic status and prosthetic need of the institutionalized elderly living in geriatric homes in mangalore: a pilot study. International Scholarly Research Notices. 2011;2011.

[17]. Shetty MS, Prabhu UM, Malli P, Shenoy R. Prosthetic Status and Demand for Services in an Adult Rural Population in Relation to Dental Service Infrastructure in Mangalore Taluk, South India. Indian Journal of Public Health Research \& Development. 2020 Feb 1;11(2).

[18]. Parlani S, Tripathi A, Singh SV. Increasing the prosthodontic awareness of an aging Indian rural population. Indian J Dent Res. 2011 MayJun;22(3):367-70. Pubmed PMID: 22048572.

[19]. Slade GD, Spencer AJ. Social impact of oral conditions among older adults. Aust Dent J. 1994 Dec;39(6):358-64. Pubmed PMID: 7832683

[20]. Shah VR, Shah DN, Parmar CH. Prosthetic status and prosthetic need among the patients attending various dental institutes of ahmedabad and gandhinagar district, gujarat. J Indian Prosthodont Soc. 2012 Sep;12(3):1617. Pubmed PMID: 23997466. 